\title{
ON NONSTANDARD POTENTIALS IN A STEFAN PROBLEM *
}

\author{
Igor Malyshev \\ Department of Mathematics and Computer Science \\ San Jose State University, San Jose, CA 95192
}

\begin{abstract}
We report some results on nonstandard potentials and their application to solution of the Stefan problem.
\end{abstract}

Key words: Stefan problem, heat potentials, integral equations

AMS subject classifications: $\quad 35 \mathrm{R} 30,35 \mathrm{R} 35$

The technique presented here is a significant improvement over that described in [1-2], since it allows the reduction of the problem below to a non-singular system of integral equations. Let us consider the following Stefan problem:

(1) $\frac{\partial \mathrm{u}}{\partial \mathrm{t}}-\frac{\partial^{2} \mathrm{u}}{\partial \mathrm{x}^{2}}=0, \quad \mathrm{x}>\mathrm{s}(\mathrm{t}), \quad \mathrm{t}>0$;

(2) $\quad \mathrm{u}(\mathrm{x}, 0)=0, \quad \mathrm{x} \geq 0, \quad \mathrm{~s}(0)=0$;

(3) $\quad \mathrm{u}(\mathrm{s}(\mathrm{t}), \mathrm{t})=\mathrm{r}(\mathrm{t}), \mathrm{t} \geq 0, \mathrm{r}(0)=0$;

(4) $\lim _{(x, t) \rightarrow(s(t), t)} \frac{\partial u}{\partial x}=\frac{d s}{d t}+h(t) \equiv p(t)+h(t)$,

* Received: October, 1989. Revised: January, 1990. 
where $s(t)$ is a continuously differentiable function, not necessarily monotonous.

We are looking for $u(x, t)$ in the form

$$
u(x, t)=\int_{0}^{t} v(x, \gamma) d \gamma,
$$

where $\mathrm{V}$ is a standard single-layer heat potential:

$$
\mathrm{V}(\mathrm{x}, \gamma)=\frac{1}{2 \sqrt{\pi}} \int_{0}^{\gamma} \frac{\mu(\tau)}{\sqrt{\gamma-\tau}} \mathrm{e}^{-\frac{(\mathrm{x}-\mathrm{s}(\tau))^{2}}{4(\gamma-\tau)}} \mathrm{d} \tau
$$

It can be proved that $u(x, t)$ in the form (5) satisfies (1)-(2), and the boundary and Stefan conditions (3)-(4) for such function $u$ are reducible to the following system of integral equations:

$$
\begin{aligned}
& p(t)=-h(t)-\int_{0}^{t} \mu(\tau) \operatorname{sgn}(s(t)-s(\tau))\left(1-\operatorname{erf}\left(\frac{|s(t)-s(\tau)|}{2 \sqrt{t-\tau}}\right)\right) d \tau, \\
& r(t)=\int_{0}^{t} \mu(\tau)\left[\sqrt{\pi(t-\tau)} e^{-\frac{(x-s(\tau))^{2}}{4(\gamma-\tau)}}-2|s(t)-s(\tau)|\left(1-\operatorname{erf}\left(\frac{|s(t)-s(\tau)|}{2 \sqrt{t-\tau}}\right)\right)\right] d \tau .
\end{aligned}
$$

The remarkable feature of this system is the regularity of its kernels, which promises advantages in the implementation of numerical methods.

The analysis of the nonstandard potentials and the unique solvability of the obtained system will be presented elsewhere.

\section{REFERENCES}

[1] Malyshev, I., Morris, H., Naroditsky, V., Romanyuk, L., Surface integrals approach to solution of some free boundary problems, J. of Applied Mathematics and Simulation, V. 1, No. 4, 305-323, (1988).

[2] Malyshev, I., Surface integrals approach to solution of some free boundary problems - II, J. of Applied Mathematics and Simulation, V. 2, No. 2, 91-100, (1989). 


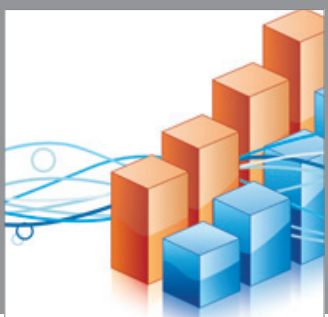

Advances in

Operations Research

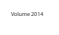

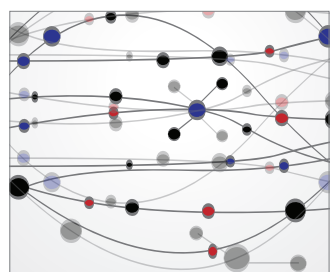

\section{The Scientific} World Journal
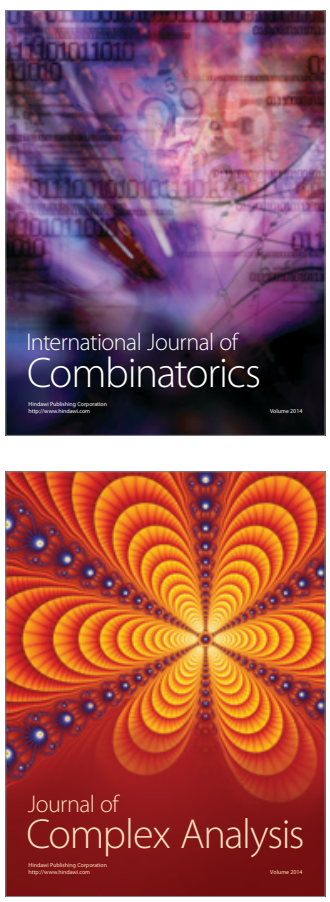

International Journal of

Mathematics and

Mathematical

Sciences
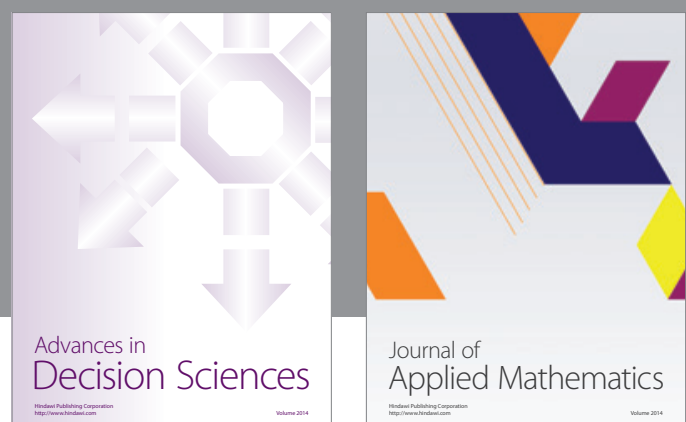

Journal of

Applied Mathematics
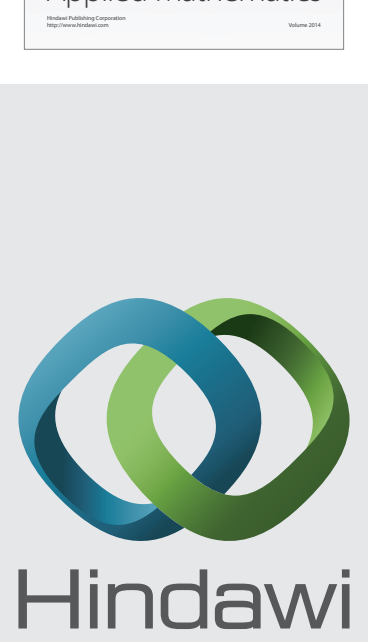

Submit your manuscripts at http://www.hindawi.com
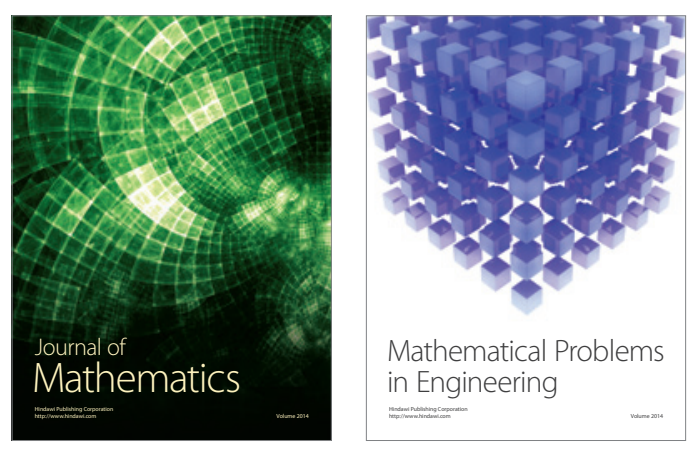

Mathematical Problems in Engineering
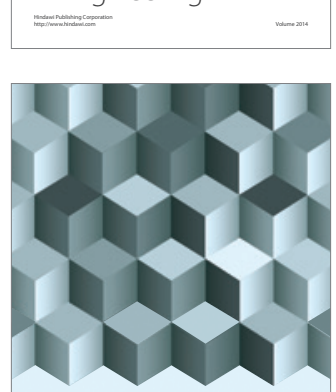

Journal of

Function Spaces
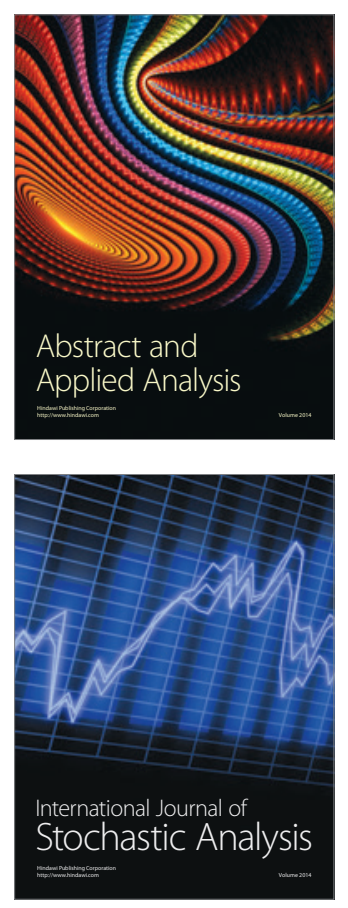

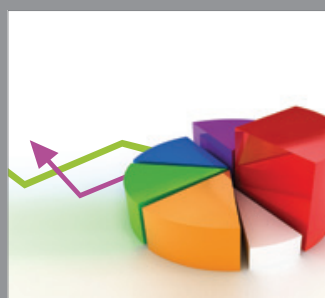

ournal of

Probability and Statistics

Promensencen
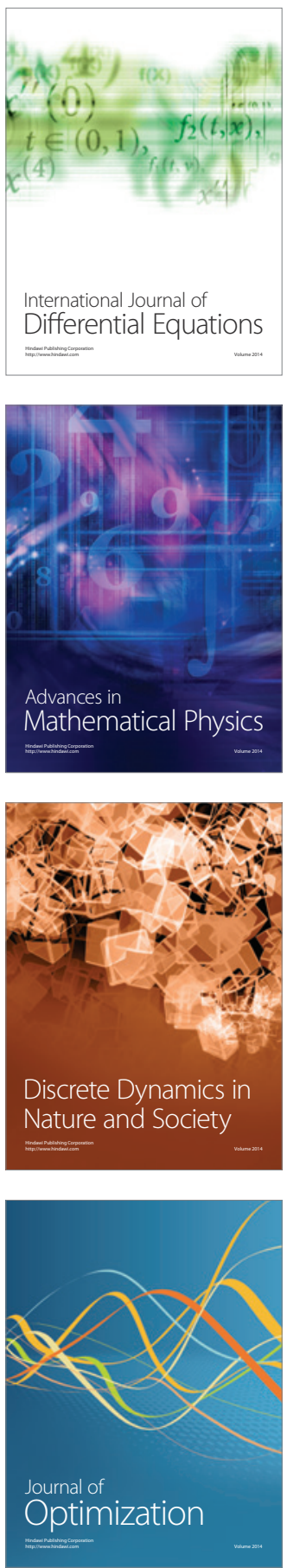